\title{
Effect of hyporheic exchange on the particle size distribution of colloids
}

\author{
ZhongTian Zhang ${ }^{1}$, Guangqiu Jin ${ }^{1}$, Hongwu Tang${ }^{1}$, Wenhui Shao ${ }^{1}$, Xiaorong Zhou ${ }^{2}$, and \\ Ling $\mathrm{Li}^{3}$ \\ ${ }^{1}$ Hohai University \\ ${ }^{2}$ Taizhou Water Conservancy Bureau \\ ${ }^{3}$ Westlake University
}

May 29, 2020

\begin{abstract}
Hyporheic exchange plays a critical role in driving the transport of colloids in the hyporheic zone, but it remains unexplored how the particle size distribution of colloids varies during their transport process. This study aims to investigate the particle size variations and effects of factors on different sized colloids via laboratory experiment and simulation. The results show that both settlement and convection-diffusion play a role in the exchange of colloids between the stream and the streambed. Settlement is the dominant factor determining the exchange of large-sized particles due to their high settling velocity; the transport of small-sized particles is affected more by convection and diffusion, and part of them can be released from the streambed to the stream; while the exchange of middle-sized particles is affected by both convection-diffusion and settlement. As the colloids can affect the environment and eco-system of hyporheic zone in both positive and negative ways, the knowledge of how size variations affect the transport patterns of colloids is significant to future studies.
\end{abstract}

\section{Hosted file}

2.Manu_DN-zhang(clean).docx available at https://authorea.com/users/316972/articles/455211effect-of-hyporheic-exchange-on-the-particle-size-distribution-of-colloids

\section{Hosted file}

1.Fig_DN.docx available at https://authorea.com/users/316972/articles/455211-effect-ofhyporheic-exchange-on-the-particle-size-distribution-of-colloids

\section{Hosted file}

3.Tab_DN.docx available at https://authorea.com/users/316972/articles/455211-effect-ofhyporheic-exchange-on-the-particle-size-distribution-of-colloids 